\title{
AC Electric Fields Associated with the Plasma Instabilities in the Equatorial Electrojet-III
}

\author{
S. SAMPATH ${ }^{\dagger}$ and T.S.G. SASTRY \\ Physical Research Laboratory, Ahmedabad, India
}

(Accepted June 10, 1978)

\begin{abstract}
Investigations of the $\mathrm{AC}$ electric fields associated with plasma instabilities in the equatorial electrojet were carried out from Thumba using Langmuir double probes. AC electric fields, the electrojet current density and the electron density and its fluctuations were measured in near simultaneous launchings on two different occasions near local noon when the electrojet intensity was high. A third experiment was conducted in the early morning hours when the electrojet was not yet developed. The two noon time experiments detected AC electric fields associated with cross field instability, both during the ascent and the descent, between 85 and $105 \mathrm{~km}$ altitude. In the early morning experiment $\mathrm{AC}$ electric fields in the spectral band $10-100 \mathrm{~Hz}$ were observed between 115 and $130 \mathrm{~km}$ altitude.
\end{abstract}

\section{Introduction}

Quasistatic AC electric fields associated with plasma instabilities in the auroral ionosphere and the magnetosphere have been studied extensively. The techniques used and the results of these investigations have been reviewed by Mozer (1973) and more recently by KeLLEY (1977). But, results from in situ probe measurements of AC electric fields associated with the plasma instabilities in the equatorial electrojet have not been reported so far. The purpose of the present paper is to report the results from three series of experiments conducted at Thumba to identify the AC $E$-fields associated with electrojet plasma instabilities.

\section{Experiments}

Table 1 shows the details of the experiments. The first series of experiments were conducted in 1972, the second series in 1973 and the third in 1975. The first two series of experiments were conducted near noon with near identical payloads. The $E$ field probes were multiple double Langmuir probes consisting of six spherical sensors, deployed four at the top and two at the bottom. The whole system is an improved version of the payload described by Mozer and Bruston (1967). The payload was designed to measure both DC and AC electric fields. In near simultaneity with the launching of the $E$ field probes, a second rocket carrying a proton magnetometer and a Langmuir probe was launched to measure electrojet current

\footnotetext{
† Present address: Radio Science Division, National Physical Laboratory, New Delhi, India.
} 
Table 1. Details of the rocket experiments conducted from Thumba, India, for the near simultaneous measurements of the electrojet current density $J$, electron density $N_{e}$ and the AC/DC electric field, in October 1972 and March 1973.

\begin{tabular}{|c|c|c|c|c|c|}
\hline $\begin{array}{l}\text { Flight } \\
\text { No. }\end{array}$ & Date & $\begin{array}{l}\text { Time } \\
\text { (IST) }\end{array}$ & Payload & Rocket & $\begin{array}{l}\text { Apogee } \\
(\mathrm{km})\end{array}$ \\
\hline 05.17 & $13-10-72$ & 1227 & $E$-Field & Centaure & 120 \\
\hline 20.16 & $13-10-72$ & 1259 & $\left.\begin{array}{l}\text { Magnetometer }(J) \\
\text { Langmuir Probe }\left(N_{e}\right)\end{array}\right\}$ & Nike Apache & 160 \\
\hline 05.19 & $03-03-73$ & 1135 & $E$-Field & Centaure & 120 \\
\hline 20.17 & 03-03-73 & 1224 & $\left.\begin{array}{l}\text { Magnetometer }(J) \\
\text { Langmuir Probe }\left(N_{e}\right)\end{array}\right\}$ & Nike Apache & 160 \\
\hline P-158 & $09-02-75$ & 0559 & $\left.\begin{array}{l}\text { E-Field Probe } \\
\text { Langmuir Probe }\left(N_{e}\right)\end{array}\right\}$ & Petrel & 140 \\
\hline
\end{tabular}
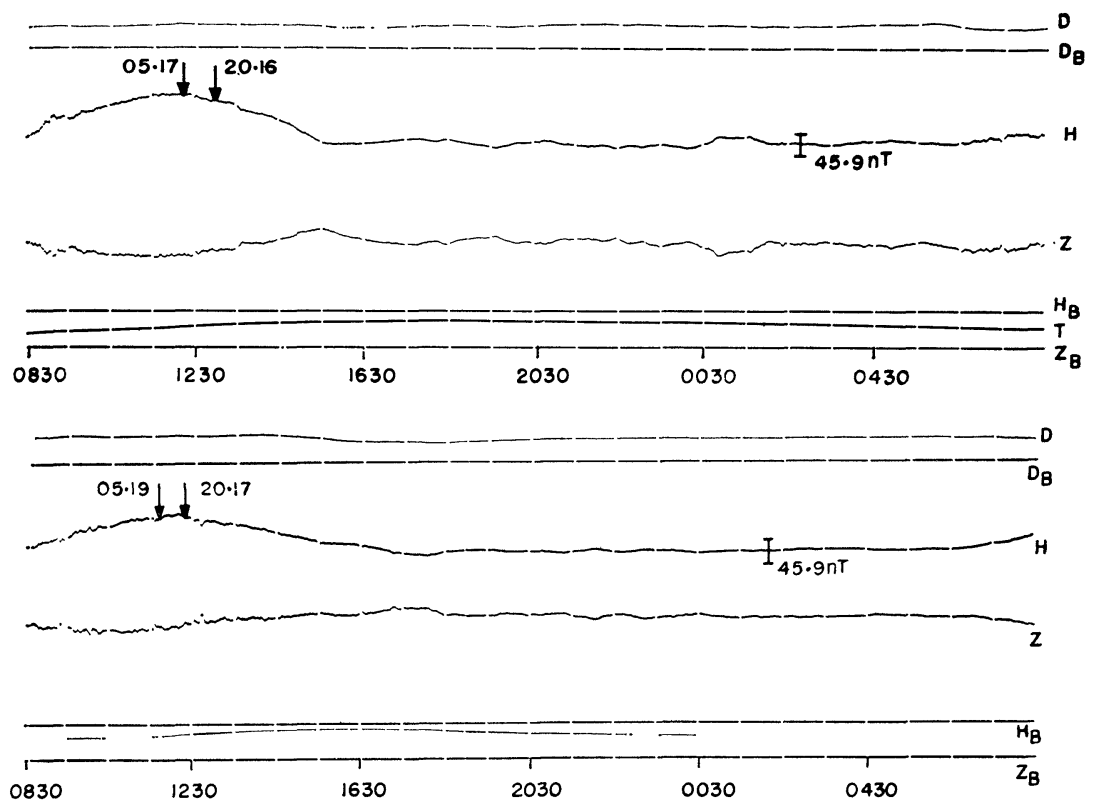

Fig. 1. Trivandrum magnetograms. Top: 1972 October, $13^{\mathrm{d}} 08^{\mathrm{h}} 34^{\mathrm{m}}$ to $14^{\mathrm{d}} 08^{\mathrm{h}} 30^{\mathrm{m}}$ IST; $H$ baseline value $=39,581 \mathrm{nT}$; time of launch FL 05.17, 1227 IST; FL 20.16, 1259 IST. Bottom: $1973 \mathrm{March}^{0} 03^{\mathrm{d}} 08^{\mathrm{h}} 33^{\mathrm{m}}$ to $04^{\mathrm{d}} 08^{\mathrm{h}} 30^{\mathrm{m}}$ IST; $H$ baseline value $=39,562 \mathrm{nT}$; time of launch FL 05.19, 11.35 IST; FL 20.17, 12.24 IST.

density and electron density respectively. The geomagnetic condition during the two series of launchings is shown in Fig. 1.

The third experiment was conducted during the early morning hours. The $E$ field probe in this experiment was of Beryllium-Copper BI-STEM type with effective length of $5 \mathrm{~m}$. Langmuir probe used for measuring electron density and its fluctuations was of the type described by Prakash and Subbaraya (1967). Since electrojet intensity was expected to be low at the time of this launch no magnetometer was included in this experiment. 


\section{Results: Mid-Day Experiments}

Figure 2 shows the sample of output from one of the horizontal electric field probes during the descent of FL 05.19 when it was going through the lower electrojet region. The low frequency wave is due to $V \times B$ induced electric fields. Superposed on the LF wave, one can see fluctuations of higher frequency around the peaks and troughs of the LF waves. This means that the higher frequency fluctuations observed are confined to east-west directions and are not seen when the probes are aligned in the north-south direction.

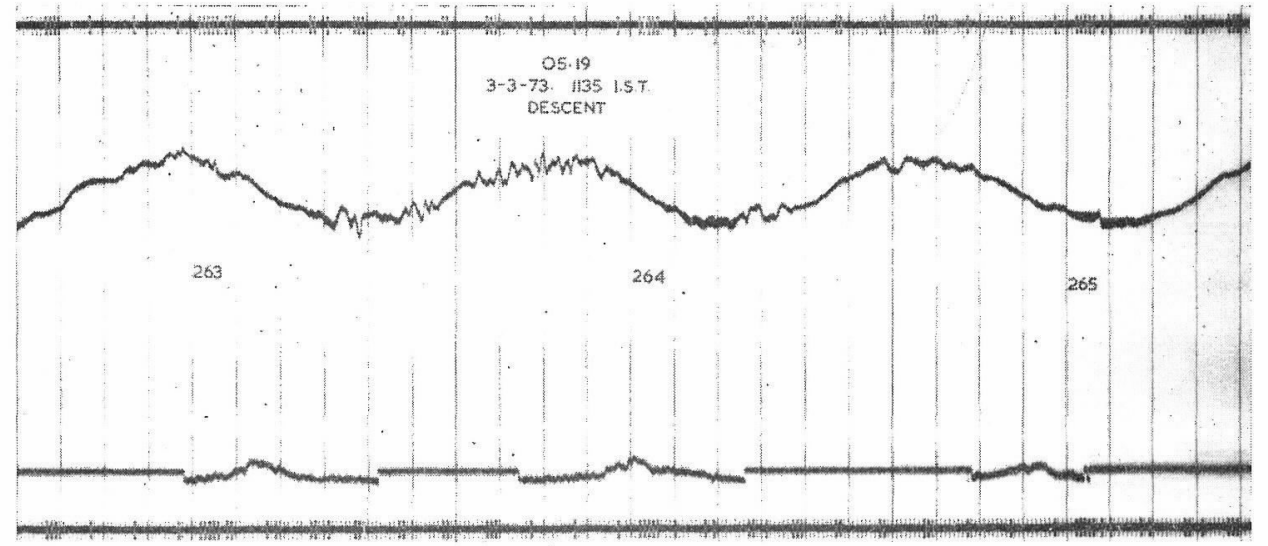

Fig. 2. Sample chart record of raw data of horizontal electric field during a portion of the descent of FL 05.19. The low frequency wave appearing at the $\mathrm{Spin}$ frequency $\approx 1 \mathrm{~Hz} / \mathrm{sec}$, is due to the $V \times B$ induced electric field. The modulations seen on this LF wave are due to AC electric field generated by plasma instability. The fluctuations are seen in the eastwest direction only (peaks and troughs of the LF wave) and are not seen in the magnetic North-South direction.

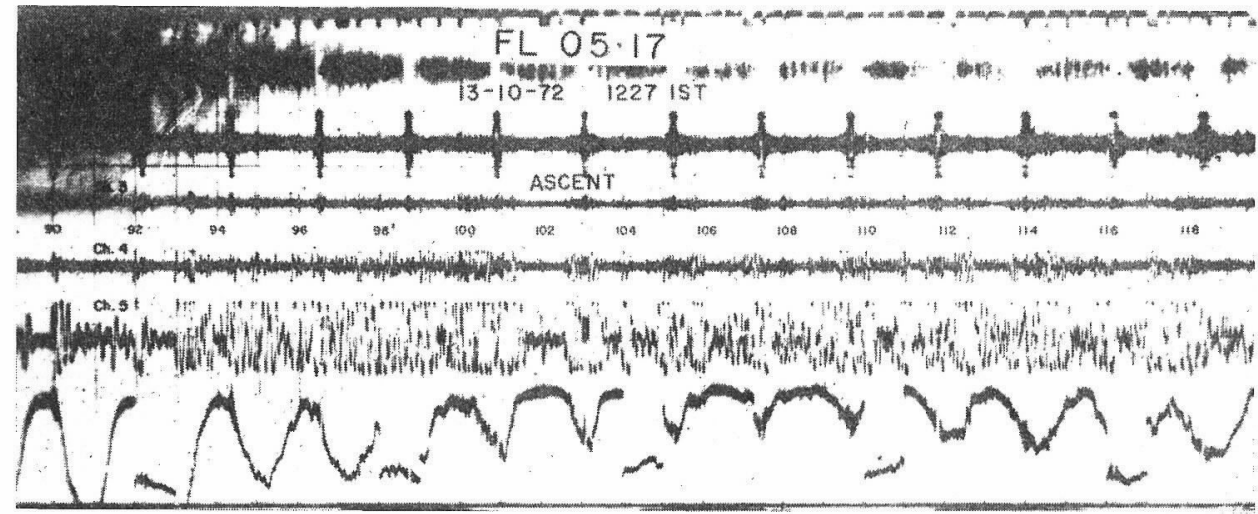

Fig. 3. Galvanometric chart record of the raw horizontal electric field data (bottom most channel) and the outputs of the five channel spectrum analyser are shown for the ascent of FL 05.17 between 88 and $115 \mathrm{sec}$. The presence of $\mathrm{AC}$ electric field can be seen in channels 3,4 and 5 from 93 to $115 \mathrm{sec}$, corresponding to the altitude range 87 to $103 \mathrm{~km}$. The large pulses seen in Ch. 2 at regular intervals of $2.2 \mathrm{sec}$ are due to spurious oscillations. 
The AC component of horizontal electric field measured during the experiments was spectrally analysed on the ground using a five channel spectrum analyser. The lowest frequency channel $\mathrm{Ch} .5$ has a center frequency of $10 \mathrm{~Hz}$, and the other channels four to one are centered at $30,90,250$ and $750 \mathrm{~Hz}$ respectively. Figures 3 to 6 show the telemetry output from $E$ field measurement at the bottom, which appears as a low frequency wave. The results of spectral analysis of AC electric field measured during the passage of the payload through the electrojet is shown arranged in five successive channels.

Figures 3 and 4 show the results of analysis of $E$ field measured during the ascent and the descent respectively of flight 05.17. The data from the ascent is not particularly good, being disturbed by a spurious oscillation recurring at $2.2 \mathrm{sec}$ intervals. The data between these intervals however appears reliable. This spurious interference is absent during the descent (Fig. 4) and the data is good.

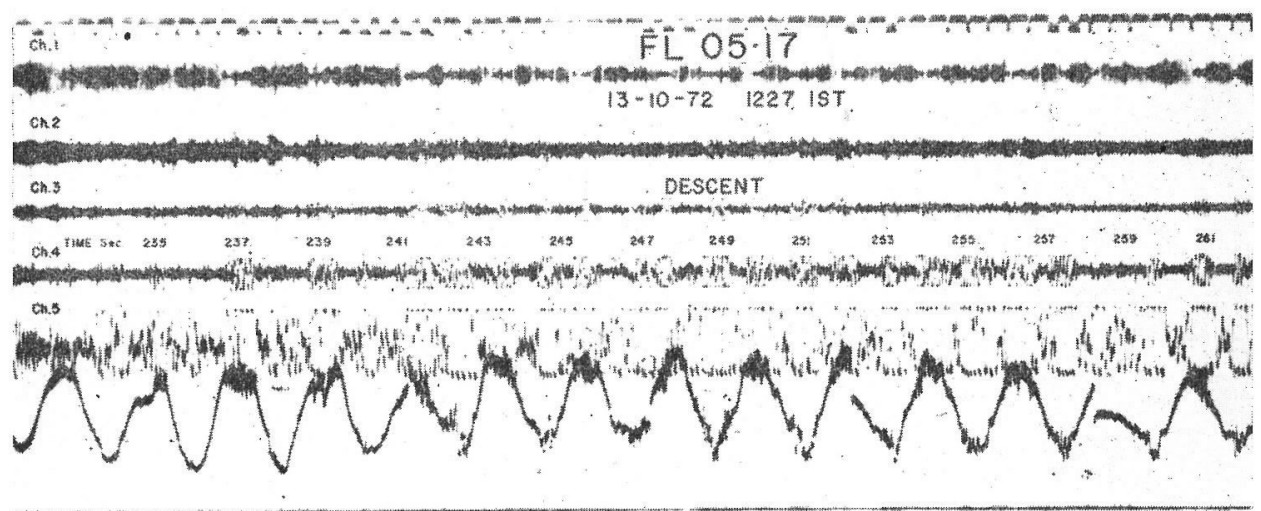

Fig. 4. The raw, horizontal $E$ field data and the spectrum analyser outputs are shown for: the descent of FL 05.17 between 232 and $260 \mathrm{sec}$. The presence of $\mathrm{AC}$ electric field can be seen in channels 3,4 and 5 between 235 and 258 sec corresponding to the altitude range of 104 to $88 \mathrm{~km}$.

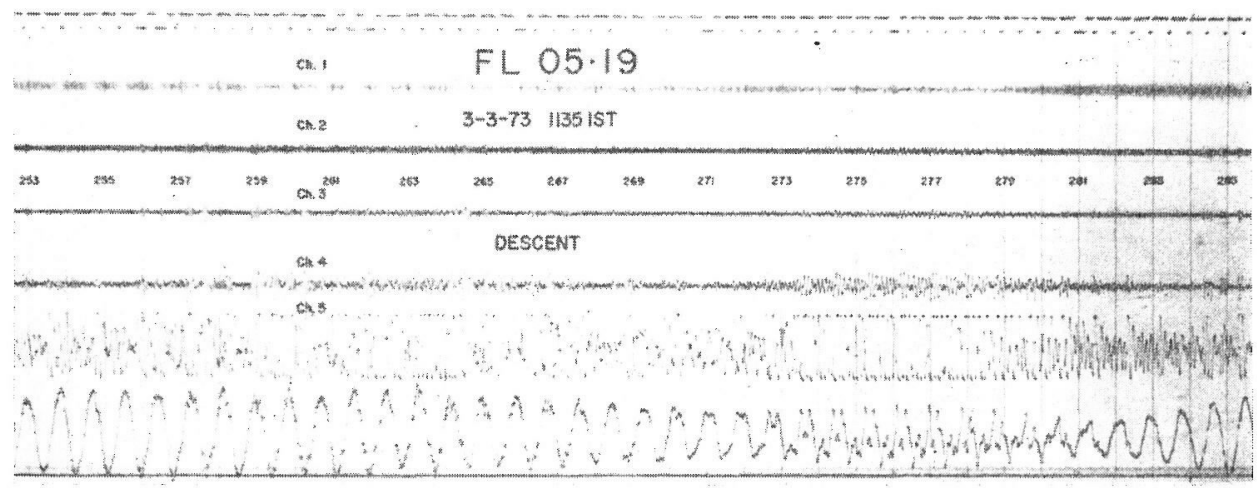

Fig. 5. The raw horizontal $E$ field data and the outputs of the spectrum analyser are shown for the ascent of FL 05.19 between 88 and $115 \mathrm{sec}$. Presence of AC electric field can be noticed in channels 3, 4 and 5 between 92.5 and $109 \mathrm{sec}$, corresponding to altitude range of 88 and $102 \mathrm{~km}$. 


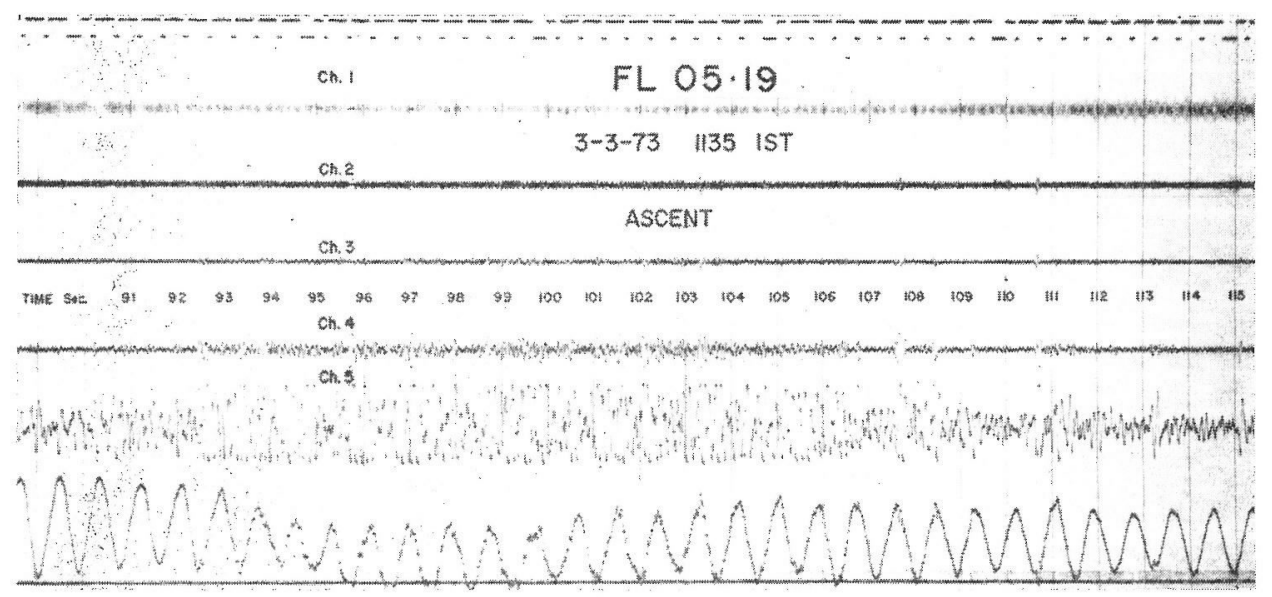

Fig. 6. The raw horizontal $E$ field data and the outputs of the spectrum analyser are shown for the descent of FL 05.19 between 253 and $280 \mathrm{sec}$. The presence of AC electric field can be seen in channels 3,4 and 5 between 256 and $269 \mathrm{sec}$ corresponding to an altitude range of 98 and $86 \mathrm{~km}$. The large modulations beyond $273 \mathrm{sec}$, are due to rocket recutry.

During the ascent (Fig. 3) it can be seen that AC field fluctuations occur in channels 3,4 and 5 between 93 and $115 \mathrm{sec}$ which corresponds to 87 and $103 \mathrm{~km}$ in altitude. The amplitude of AC field is the largest in the lowest frequency channel and is absent in 250 and $750 \mathrm{~Hz}$ channels.

During the descent of the same flight (Fig. 4) the presence of AC electric field can be clearly seen in Ch. 3, 4 and 5 between 235 and 258 sec corresponding to the altitude of 104 and $88 \mathrm{~km}$.

Figures 5 and 6 show the results from flight 05.19 measurements. The data from this flight is excellent and features similar to those observed in Figs. 3 and 4 of flight 05.17 can be clearly seen. During the ascent, the presence of AC electric field is more prominently seen in lower frequency channels 3,4 and 5 between 92 and $109 \mathrm{sec}$ corresponding to 88 and $102 \mathrm{~km}$ altitudes respectively. During the descent (Fig. 6) perturbations due to AC electric field can again be seen in LF channels 3,4 and 5 between 256 and $269 \mathrm{sec}$ corresponding to 98 and $86 \mathrm{~km}$ respectively. The fluctuations beyond $273 \mathrm{sec}$ in this figure are due to the rocket reentry into the atmosphere and must be ignored.

Figure 7 shows the electrojet current density $J$ and electron density $N_{e}$ measured nearly simultaneously with the measurement of $\mathrm{AC}$ electric field. Around the dip equator the Hall polarization field $E_{z}$ can be taken as directly proportional to current density $J$, (Sugiura and Poros, 1969), hence the $E_{z}$ profile has the same form as the $J$ profile.

\section{Discussion of Results}

In Fig. 7 it can be seen that the gradient in electron density $\mathrm{d} N_{c} / \mathrm{d} h$ and the Hall potential $E_{z}$ both point upwards between 90 and $104 \mathrm{~km}$ altitude. The magnetic 


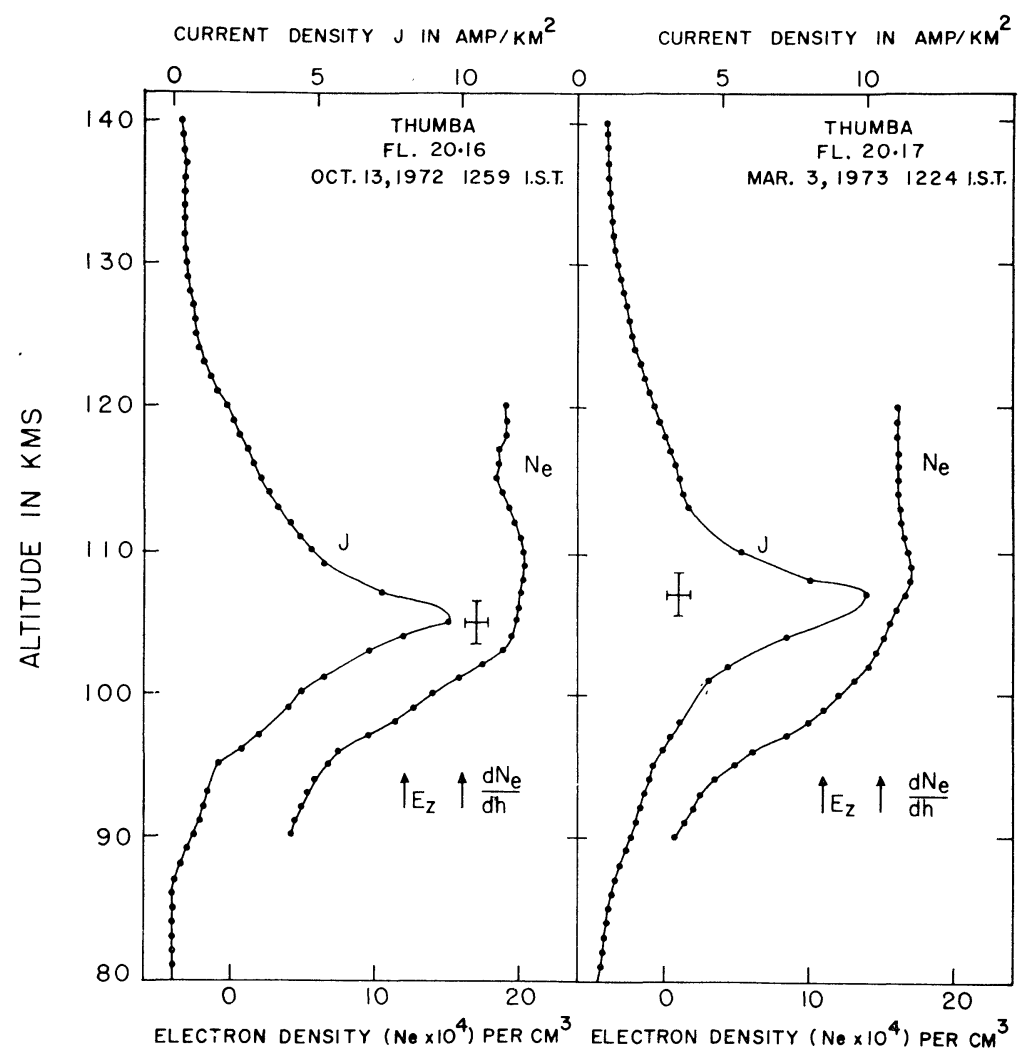

(a)

(b)

Fig. 7. (a) The electrojet current density $J$ and the electron density $N_{e}$ measured during the flight 20.16. The gradient in electron density and the Hall field point upwards between the altitudes 90 and $105 \mathrm{~km}$. (b) The electrojet current density $J$ and the electron density $N_{e}$, measured during the flight 20.17. The gradient in electron density and the Hall field point upward between the altitudes 90 and $103 \mathrm{~km}$.

field is horizontal and directed northwards. This is the region one would expect the cross field instability. Results from FL 05.17 (Figs. 3 and 4) and from FL 05.19 (Figs. 5 and 6) show the AC electric field fluctuations in the above region between 87 and $104 \mathrm{~km}$. Hence the observed AC electric field fluctuations must be due to the presence of cross field instability in this region. The fact that the AC electric field fluctuations are seen prominently in channels 3,4 and 5 shows that the frequency of the observed $\mathrm{AC}$ electric field lies in the range $5 \mathrm{~Hz}$ and $120 \mathrm{~Hz}$ which are the lower and upper limits of channels 3 and 5 respectively.

In the above experiments the drift velocity of electrons $V_{d}$ as derived from equation $J=V_{d} N_{e} \cdot e$ exceeds the threshold for the generation of type $I$ irregularities in the region around the peak of the electrojet. But no AC electric field attributable to the two stream instability was detected in these flights. The amplitude of AC electric field due to the two stream instability is expected to be small compared to 
that due to the cross field instability. Non-detection of $\mathrm{AC}$ electric field due to the two stream instability in these experiments could be due to the low gain of the electric field detector used.

\section{Results from the Early Morning Experiment P-158}

In this experiment, unlike in the previous experiments 05.17 and 05.19 , the $E$ field measured was analysed by an on board spectrum analyser into three frequency bands, Ch. 1, 10 to $100 \mathrm{~Hz}$, Ch. 2, $100 \mathrm{~Hz}-1 \mathrm{kHz}$ and Ch. $3,1 \mathrm{kHz}-10 \mathrm{kHz}$. The outputs were telemetered and recorded at the ground. The results presented in Fig. 8 show the fluctuations of average AC electric field in the three frequency bands. The electron density profile obtained by Gupta, (Rees et al., 1975) from a Langmuir probe experiment on board the same rocket is shown at the top.
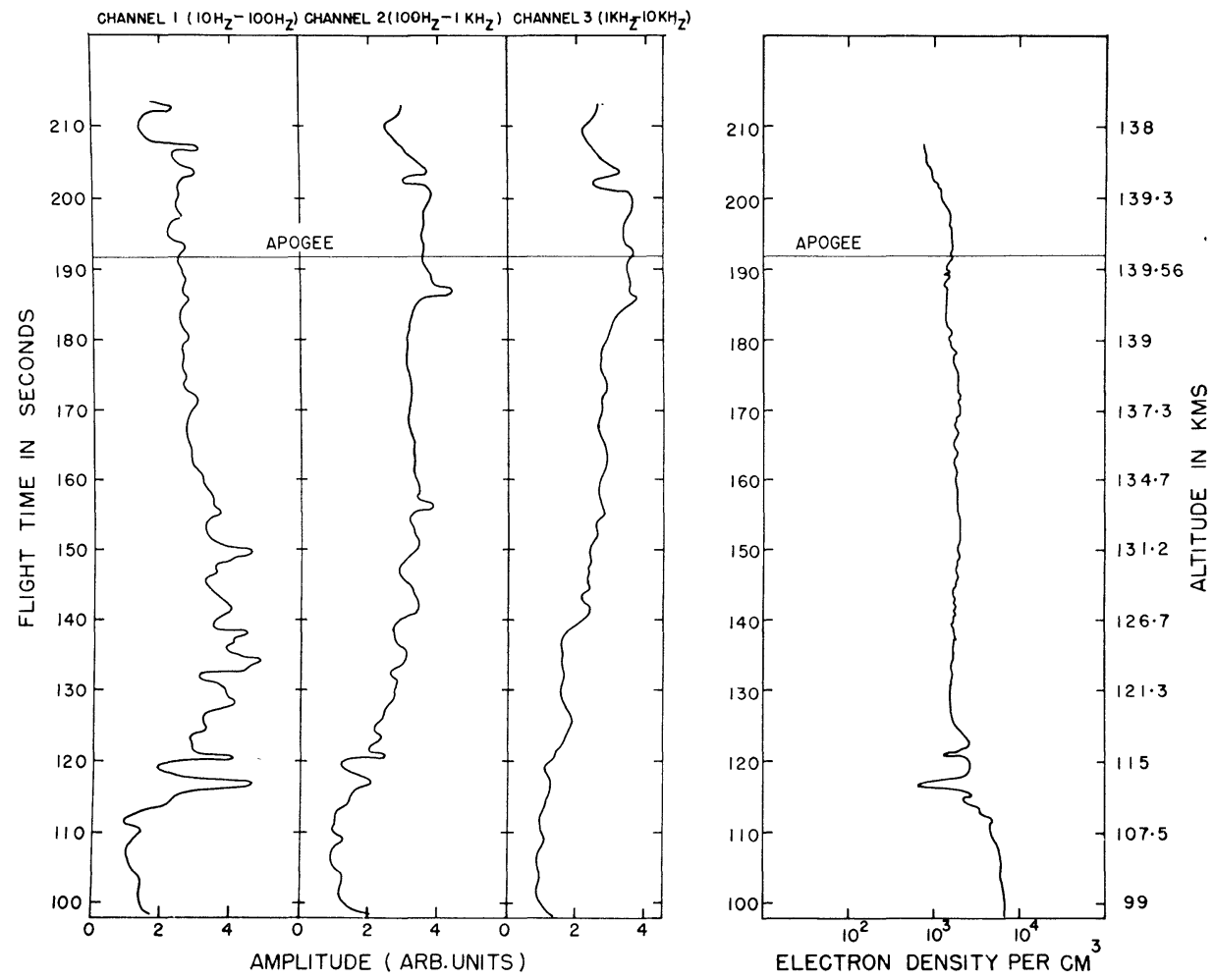

Fig. 8. The average levels of the AC electric field in three spectral bands, $10 \mathrm{~Hz}$ to $100 \mathrm{~Hz}$ (Channel 1), $100 \mathrm{~Hz}$ to $1 \mathrm{kHz}$ (Channel 2) and $1 \mathrm{kHz}$ to $10 \mathrm{kHz}$ (Channel 3), measured during the flight P-158 are shown together with the electron density measurements made on the same flight. Large amplitude AC electric field fluctuations in the frequency band of $10 \mathrm{~Hz}$ to $100 \mathrm{~Hz}$, were detected between 110 and $131 \mathrm{~km}$. The AC electric field in channel 1 and the electron density, show large changes in the same altitude interval, 110 to $120 \mathrm{~km}$. The large enhancement of AC electric field around the apogee, seen in the high frequency channels 2 and 3 , is due to the rocket induced effects. 
It is seen from Fig. 8 that the largest fluctuations in the AC electric field occur in the lowest frequency band, $10 \mathrm{~Hz}-100 \mathrm{~Hz}$ and that the average level of the $\mathrm{AC}$ electric field of different frequency bands do not vary in the same way with the altitude. The level of the AC electric field of 10 to $100 \mathrm{~Hz}$ band remains quiet between $100 \mathrm{~km}$ and $108 \mathrm{~km}$, then it increases sharply near $110 \mathrm{~km}$ and shows a broad maximum superposed by large fluctuations between 110 and $131 \mathrm{~km}$. Thereafter, the average $\mathrm{AC}$ field level remains steady and quiet towards the apogee. It can be seen that both the low frequency $(10-100 \mathrm{~Hz}) \mathrm{AC}$ electric field and the electron density measured on the same flight show large changes in the same altitude range 110 and $120 \mathrm{~km}$.

The level of AC electric field of $100 \mathrm{~Hz}$ to $1 \mathrm{kHz}$ band (Ch. 2 output) is also quiet between 100 and $110 \mathrm{~km}$, then it increases gradually up to $129 \mathrm{~km}$ with observable fluctuations similar to those seen in the low frequency channel output $\mathrm{Ch}$. 1. The AC field is steady and quiet between 133 and $139 \mathrm{~km}$ and just before the apogee, a sudden increase in the field is observed. The field remains significantly high on either side of the apogee.

The AC field level in the frequency band $1 \mathrm{kHz}-10 \mathrm{kHz}$ steadily increases right from $100 \mathrm{~km}$ upto the apogee with small fluctuations superposed on the average level. Fluctuations similar to those observed in the lower frequency channels between 110 and $130 \mathrm{~km}$ are absent in this channel output. However, as in Ch. 2, here also there is a significant enhancement in the AC field level around the apogee.

\section{Discussion of Results}

In the results presented in Fig. 8, two striking features can easily be observed. First, the AC field in the lowest frequency band $(10 \mathrm{~Hz}-100 \mathrm{~Hz})$ goes through a broad maximum between 110 and $131 \mathrm{~km}$, and shows large changes in intensity in the same region where the electron density also undergoes large changes. The maximum around the apogee which is the characteristic feature of the higher frequency channels 2 and 3 is not noticeable in the profile of channel 1. The electron density measured on the same flight shows regions of downward electron density gradients in the altitude intervals $108-113 \mathrm{~km}, 115-116 \mathrm{~km}$ and $117-120 \mathrm{~km}$. Gupta (private communication) has detected significant electron density fluctuations at the above mentioned regions of downward electron density gradients. He has ascribed the observed electron density fluctuations to the presence of cross field instability in these regions. It can be seen from the figure that the $\mathrm{AC}$ electric field intensity also increases in the regions of downward electron density gradients where cross field instability has been observed. Hence the observed low frequency $E$ field fluctuations can be due to the cross field instability in this region.

The second prominently observable feature in Fig. 8 is the enhancement of AC electric field level around the apogee in the higher frequency channels Ch. 2 and Ch. 3. Alpert et al. (1963) have shown that a vehicle moving in an ionised medium can produce longitudinal ion oscillations in its wake, when the velocity of the 
vehicle becomes subsonic. In the apogee region the velocity of the rocket becomes subsonic. Also, near the apogee the rocket moves horizontally and one of the probes will be within the wake for the good part of a spin cycle. Under these conditions the electric field probe will be in a position to detect the AC electric field in the wake due to rocket motion. There is some evidence to show that the AC electric field detected in the apogee region must be due to longitudinal ion oscillations in the wake. Gurevich et al. (1969) have estimated the frequency of ion oscillations in the rocket wake to be in the range of 0.1 to 1 times the ion plasma frequency in the region. At the time of the flight, the electron density near the apogee altitude $140 \mathrm{~km}$, was $5 \times 10^{3}$ electrons $/ \mathrm{cm}^{3}$. Assuming the ion density is equal to the observed electron density, the ion plasma frequency works out to be about $1 \mathrm{kHz} .1 \mathrm{kHz}$ is near the upper band edge of Ch. 2 and also near the lower band edge of Ch. 3 . Hence, both channels 2 and 3 show the enhancement of AC field around the apogee with equal prominence. Hence, the observed $\mathrm{AC}$ field enhancement near the apogee could be due to the longitudinal ion oscillations in the rocket wake.

\section{Conclusions}

1) The two rocket-borne electric field experiments conducted near local noon from Thumba detected for the first time, AC fluctuations in the horizontal component of electric field, associated with the plasma instabilities within the electrojet. These electric field fluctuations were seen between 85 and $105 \mathrm{~km}$ altitudes during both the ascent and the descent in two independent rocket experiments.

2) The observed electric field fluctuations are due to the cross field instability, generated in the altitude region of 85 to $105 \mathrm{~km}$ where the electron density gradient and the vertical Hall field are parallel and upward.

3) The frequency of the observed fluctuations lies in the range of $5 \mathrm{~Hz}$ to 120 $\mathrm{Hz}$ and are seen in the east-west direction only. No significant fluctuations in $E$ field were seen in the magnetic north-south direction along the field line.

4) No AC electric field attributable to type I irregularities was detected in the experiments. This could be due to the low gain of the $E$ field detector system used in the experiment.

5) In the early morning experiment, AC electric field fluctuations associated with the cross field instability were seen in the low frequency band $10 \mathrm{~Hz}-100 \mathrm{~Hz}$ between $115-130 \mathrm{~km}$, especially in the regions of downward electron density gradient.

6) Rocket generated electric field fluctuations were detected around the apogee, the frequency of $\mathrm{AC}$ field being $1 \mathrm{kHz}$. The detected electric field could be due to the longitudinal ion oscillations in the wake.

The authors are grateful to Prof. Blamont and Dr. Sartiel of CNES, France for allowing them to use some of the data from electric field experiments obtained during rocket borne experiments conducted in collaboration with them. Authors wish to thank Prof. B.N. Bhargava, Director, Indian Institute of Geomagnetism for the magnetic data from Trivandrum magnetic observatory and Dr. S.P. Gupta for the information concerning electron density measurements used in this paper. 
The cooperation rendered by the personnel of the Thumba Equatorial Rocket Launching Station in making the rocket flights a success is highly appreciated. In particular the authors are thankful to Mr. R. Aravamudan and Mr. V. Sudhakar for their help in various stages of the rocket campaign.

\section{REFERENCES}

Alpert, Y.L., A.V. Gurevich, and L.P. Pitaevskit, On the effects produced by a fast-moving body in a plasma, Space Res., III, 1224-1271, 1963.

Gurevich, A.V., L.P. PitaevskiI, and V.V. Smirnova, Ionospheric aerodynamics, Space Sci. Rev., 9, 805-871, 1969.

Kelley, M.V., Observations of electrostatic waves on auroral field lines, SIII-3C, session on electromagnetic andele ctrostatic instabilities on auroral field lines, GA 519, IAGA/IAMAP joint assembly, Seattle, 1977.

Mozer, F.S., Analysis of techniques for measuring DC and AC electric fields in the magnetosphere, Space Sci. Rev., 14, 272-313, 1973.

Mozer, F.S. and P. Bruston, Electric field measurements in the auroral ionosphere, J. Geophys. Res., 72(3), 1109-1114, 1967.

Prakash, S. and B.H. Subbaraya, Langmuir probe for the measurement of electron density and electron temperature in the ionosphere, Rev. Sci. Instrum., 38, 1132-1136, 1967.

Rees, D., P.D. Bhavsar, J.N. Desai, S.P. Gupta, A.D. Farmer, and P. Rounce, Preliminary report on the Commonwealth collaborative rocket launch programme from the Thumba Equatorial Racket Launching Station for the investigation of atmospheric and ionospheric processes, Space Res., XVI, 407-412, 1975.

Sugiura, M. and D.J. Poros, An improved model of equatorial electrojet with a meridional current system, J. Geophys. Res., 74, 4025-4034, 1969. 